\title{
Centralized Services
}

\section{In New Central Washington Building}

BY CLARENCE GORCHELS

$\mathrm{A}^{\mathrm{R}}$ RCHitects, builders, and administrators have achieved a high degree of integrated variety in the new library building (completed in October 1961) on the campus of Central Washington State College, Ellensburg, Washington.

The architects and builders have combined such features as ultramodern precast and prestressed roof panels, spectacular sunscreens, a landscaping plan to counteract the effect of bigness, and a unique "medieval" method of providing artistic attractions.

Administratively, the following groups of resources and services are closely integrated in the new library building: closed-circuit-television services, audiovisual materials, the curriclum laboratory, the instructional-materials-production laboratory, and the traditional library. Thus, students and faculty have access in this new educational resources center to the books, films, phonodiscs, periodicals, art prints, tapes, etc., which are required for modern study, teaching, and educational research. A full-time staff of fifteen, including librarians, audio-visual experts, and other specialists work under the supervision of the director to provide coordinated services.

Initially, seats are available for 855 of the 2,600 students at Central, and shelving is in place for 112,000 volumes. Considerable space has been provided for expansion, since enrollment is increasing at a high rate.

The architectural design of the building, especially the use of precast, prestressed roof panels, has attracted consid-
Mr. Gorchels is Librarian, Central Washington State College.

erable attention in the world of architecture. Each of the ninety-eight unique roof elements spans sixty-five feet, accomplishing noteworthy floor-plan flexibility in eliminating the necessity for numerous inside columns. Moreover, the manufacture of these panels using concrete to resist compression stresses and steel wires to resist tensile stresses makes possible a saving of about one-half of the concrete and one-third of the steel normally needed to roof a building of this size.

The window-walls on the east and west sides of the building are protected by clay-tile sunscreens resembling long honeycombs. Visibility is excellent for readers who wish to look out at the Kittitas Valley landscape, but direct sunshine and glare are effectively prevented from coming into the building. The south wall of the building has only six hooded windows.

The outside dimensions of the twostory building are 156 by 224 feet, and the architects have endeavored to elimininate the appearance of massiveness. Architect Fred Bassetti has explained his method: "We have mass communication, mass transportation and mass education, but through a serious concern for human scale we have tried to shape the site and the building to a size proportioned for the users. This is done in the site plan 
by holding the plaza (which is a gathering place for students) to the smallest area consistent with its campus location, and by planting a 'bosque' in front of the building. This is a grid of plane trees which creates space by dividing it on about a thirty-foot module of columnar tree trunks. This will provide shade and wind protection in spring and summer, while letting the sun filter through in winter, since the trees are deciduous."

To achieve artistic beauty throughout the new library building the architect engaged five artists to execute appropri- ate paintings and sculpture in the building itself rather than produce studio art to be brought into the building. The artists lived on the campus for approximately two months, working together in the incomplete building and in the college shops. Again, Architect Bassetti has stated the objective: "It is our intention to encourage the placement, not of one monumental work at the entry, but rather of many smaller, more human works of art, fitted lovingly into any part of the building which strikes the artist's fancy and which can be seen and studied

The Central Washington State College Library, Ellensburg

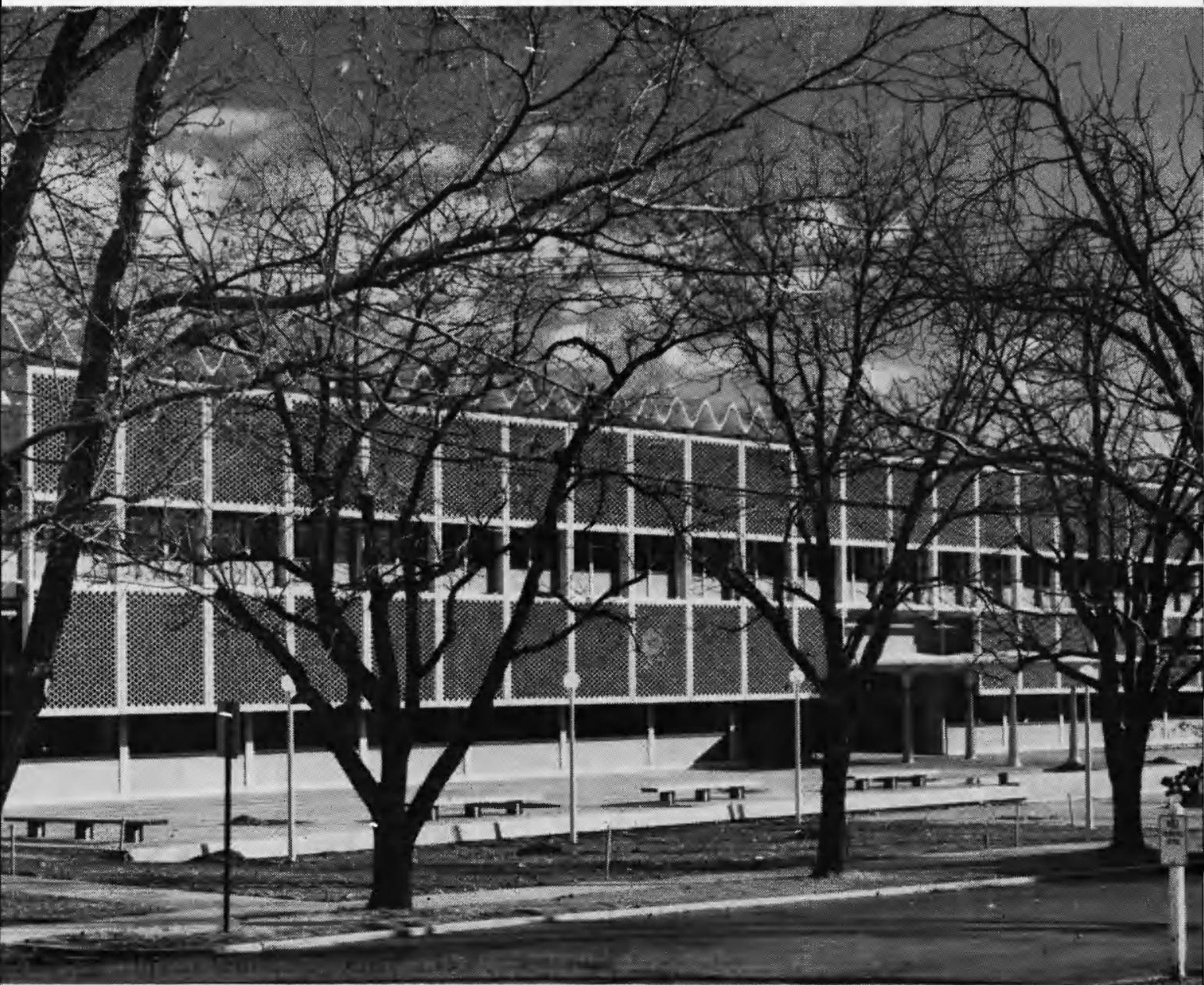


and appreciated at length by a student seated rather than only by one walking by. An organic, artistic whole similar to what was achieved in Europe in medieval times is the goal we seek, in place of the thin veneer of 'artiness' which so often appears today."

Combined with this full consideration of the esthetic values is the practical and efficient arrangement of service areas in the new building. The main service desks for the circulation of books and audiovisual materials are located on the first floor near the entrance of the building. The technical services division staff (centralized for the acquisition and processing of all types of materials) has its work area adjoining the card catalog, the reference area, and the audio-visual offices. The director's office, and work and storage space for the closed-circuit-television activities are also on the first floor.

On the second floor, separate rooms are provided for such special library materials as the music and art collection, archives, and maps. On this floor, also, are the curriculum laboratory, the instructional-materials-production laboratory, library science classrooms, audition and preview rooms, and the language laboratory.

The curriculum laboratory is an area of three thousand square feet, planned to house materials such as courses of study, subject-unit outlines, representative textbooks, workbooks, and related materials which are invaluable to teachers and future teachers.

The instructional-materials-production laboratory is equipped with work tables, appropriate machines, and supplies which are useful to teachers in creating graphic and audio-instructional materials.

The language laboratory has semiprivate booths with tape recorders, as well as classroom furnishings arranged to facilitate the study of foreign languages.

Last but not least, on both floors books and periodicals are shelved on open stacks. Most of the study chairs and tables, including sixty individual study carrels, are located among or adjacent to the open stacks.

Permanent walls are few in the new building, thus providing for maximal flexibility as the various services expand (or decline) in the future. The building can be extended to the east and to the north to take care of long-range expansion requirements.

Name of Library: Central Washington State College Library

Architect: Bassetti \& Morse, Seattle

Type of Construction: Reinforced concrete with pan joist floors and concrete slabs; precast and prestressed roof panels; clay tile sun screen.

Building costs:

Cost of site: Part of campus

Construction costs: $\$ 1,522,456$, including landscaping and decoration; $\$ 21.75$ per sq. $\mathrm{ft}$.

Lighting: Fluorescent and incandescent Floors: Vinyl asbestos tile

Heating: Campus steam system

Air conditioning: Conduits and piping only, for later installation

Book capacity (all areas): Total volume capacity: 112,000 current; 250,000 ultimate capacity; linear footage: 26,400 ; free standing shelving supplied by Ames; special wood shelving designed by architects; cost included in general contract

Stack area: Volume capacity: 105,000 current; 243,000 ultimate capacity; linear footage: 19,759; free standing stacks supplied by Ames; cost included in general contract

Library furniture: Charging desks: custom designed by architects; suppliers: Oregon Woodwork Ltd.; catalog cases, exhibit cases, tables, chairs, desks, etc.: custom designed by architects and manufactured by successful bidders in Washington, Oregon, and California, cost: $\$ 77,842$. 